\title{
Synchronization in allometric and morphological changes during metamorphosis: comparison among four sparid species
}

\author{
N. Nikolioudakis ${ }^{1, *}$, G. Koumoundouros ${ }^{2}$, S. Somarakis ${ }^{1}$ \\ ${ }^{1}$ Institute of Marine Biological Resources and Inland Waters, Hellenic Centre for Marine Research, Thalassocosmos, \\ Heraklion 71003, Crete, Greece \\ ${ }^{2}$ Department of Biology, University of Crete, PO Box 2208, 71409 Heraklion, Crete, Greece
}

\begin{abstract}
Understanding critical ontogenetic transitions in the life of fish, such as metamorphosis, is of prime importance for determining the factors that affect survival probabilities and control recruitment levels. Metamorphosis involves a plethora of changing characters and its definition requires a multi-parametric approach. In the present study, mean lengths $\left(L_{\mathrm{m}}\right)$ at allometric and morphological change during the transition from larval to juvenile phenotype were estimated with a recently introduced multi-character protocol and compared between Diplodus sargus (settling in spring), Oblada melanura (summer), D. puntazzo (autumn) and D. vulgaris (winter). $L_{\mathrm{m}}$ from allometry closely matched $L_{\mathrm{m}}$ from morphology in $D$. sargus and $D$. puntazzo but not in the winter- and summer-settling species, in which morphological transition occurred later or earlier than allometric change, respectively. $L_{\mathrm{m}}$ from allometry was very similar in the 3 Diplodus species but larger in O. melanura. The coefficients of variation of $L_{\mathrm{m}}$ from morphometric and morphological characters were negatively correlated. Morphological transitions were less synchronized but changes in allometric growth were more synchronized in $D$. vulgaris (winter) while the opposite was true for $O$. melanura (summer). This study highlights for the first time the relative importance of taxonomic relatedness and season (temperature) in determining the size at metamorphosis and the degree of synchronization (abruptness of change) both within and between mensural and morphological characters.
\end{abstract}

KEY WORDS: Metamorphosis $\cdot$ Allometry $\cdot$ Morphology $\cdot$ Sparidae

\section{INTRODUCTION}

Metamorphosis, i.e. the transition from larval to juvenile phenotype is an important event in the life cycle of fishes (Thorisson 1994, Copp \& Ková 1996, McCormick et al. 2002, Nikolioudakis et al. 2010). There is a lack of a generally agreed definition of the end of larval (onset of juvenile) period because larval development is very varied and the plethora of changing characters during metamorphosis cannot synchronize perfectly. Definitions based on single morphological criteria (e.g. squamation) are ultimately arbitrary (Urho 2002, Ditty et al. 2003) and may

${ }^{*}$ Corresponding author: niknikos@hcmr.gr impede interspecific comparisons of morphological, sensory and behavioral development (e.g. Fuiman 1994, Fuiman et al. 1998, Higgs \& Fuiman 1998, Koumoundouros et al. 2009).

In a recent publication (Nikolioudakis et al. 2010), we emphasized the importance of multi-character approaches for defining transitions, such as metamorphosis, in fish ontogeny. We used techniques to calculate length-at-metamorphosis that were based on scoring a suite of morphological characters ('multivariate morphometry') and on principal component analysis of morphometric traits ('multivariate allometry'). These techniques were applied to newly settled

() The authors 2014. Open Access under Creative Commons by Attribution Licence. Use, distribution and reproduction are unrestricted. Authors and original publication must be credited. 
white seabreams Diplodus sargus caught in spring and a high agreement was demonstrated between size-at-change in multivariate allometric growth and mean size-at-morphological transformation associated with metamorphosis (Nikolioudakis et al. 2010).

In the present paper, we extend this analysis to 3 more species of the family Sparidae (Oblada melanura, $D$. puntazzo and $D$. vulgaris) sampled from the same location in different seasons (summer, autumn and winter respectively). We compare patterns of morphological and allometric change among species (including $D$. sargus) as well as variability in the relative timing of change of the different characters in an effort to identify seasonal (i.e. temperature) effects and differences between the 2 genera.

Temperature affects the timing and rates of ontogenetic processes, with decreasing temperature slowing down the developmental rate and causing an increase in body size at specific developmental events (e.g. Fuiman et al. 1998, Koumoundouros et al. 2001). It has been hypothesized that when different morphological characters require dissimilar ontogenetic times to complete transformation, synchronization in their change will decrease with decreasing temperature (Somarakis \& Nikolioudakis 2010). In that sense, thresholds that 'saltatorists' recognize in fish ontogeny will be more abrupt (easy to define) at higher temperatures but more 'gradual' (difficult to recognize) at lower temperatures (for the 'saltatorist'-'gradualist' debate, see Ková \& Copp 1999).

Under the general framework of multi-character approaches to study metamorphosis (Ditty et al. 2003, Nikolioudakis et al. 2010, Ben Khemis et al. 2013), and using a comparative approach, we aimed at addressing 2 main questions expected to improve our understanding of ontogenetic transitions: (1) Is the close coupling of morphological transformation and allometric growth change, demonstrated in Diplodus sargus (Nikolioudakis et al. 2010), consistent across species? (2) How high is the degree of synchronization of the different morphological and morphometric traits during metamorphotic change in species from different seasons/temperature regimes?

\section{MATERIALS AND METHODS}

\section{Sampling}

The 4 sparid species, saddled seabream Oblada melanura (Linnaeus, 1758), sharpsnout seabream Diplodus puntazzo (Walbaum, 1792), common two-banded seabream D. vulgaris (Geoffroy Saint-Hilaire, 1817) and white seabream $D$. sargus (Linnaeus, 1758) were sampled in July 2005, November 2005, February 2006 and May 2006, respectively, during the period of their settlement (García-Rubies \& Macpherson 1995, Vigliola et al. 1998, Kiparissis et al. 2008) (Fig. 1). Sampling was carried out at a coastal site of the Ionian Sea (western Greece), east of the estuary of Acheloos River ( $38^{\circ} 20^{\prime} \mathrm{N}, 2^{\circ} 07^{\prime} \mathrm{E}$, Nikolioudakis et al. 2010). On each sampling occasion, the site was visited for 5 to $7 \mathrm{~d}$ during which a 1 to $2 \mathrm{~h}$ dive was performed daily and fish were caught using hand nets. More details are provided in Nikolioudakis et al. (2010). Fish were transferred live to the Laboratory of Zoology in the University of Patras, Greece and each individual was anaesthetized, photographed and finally fixed and stored in $5 \%$ borax-buffered formalin.

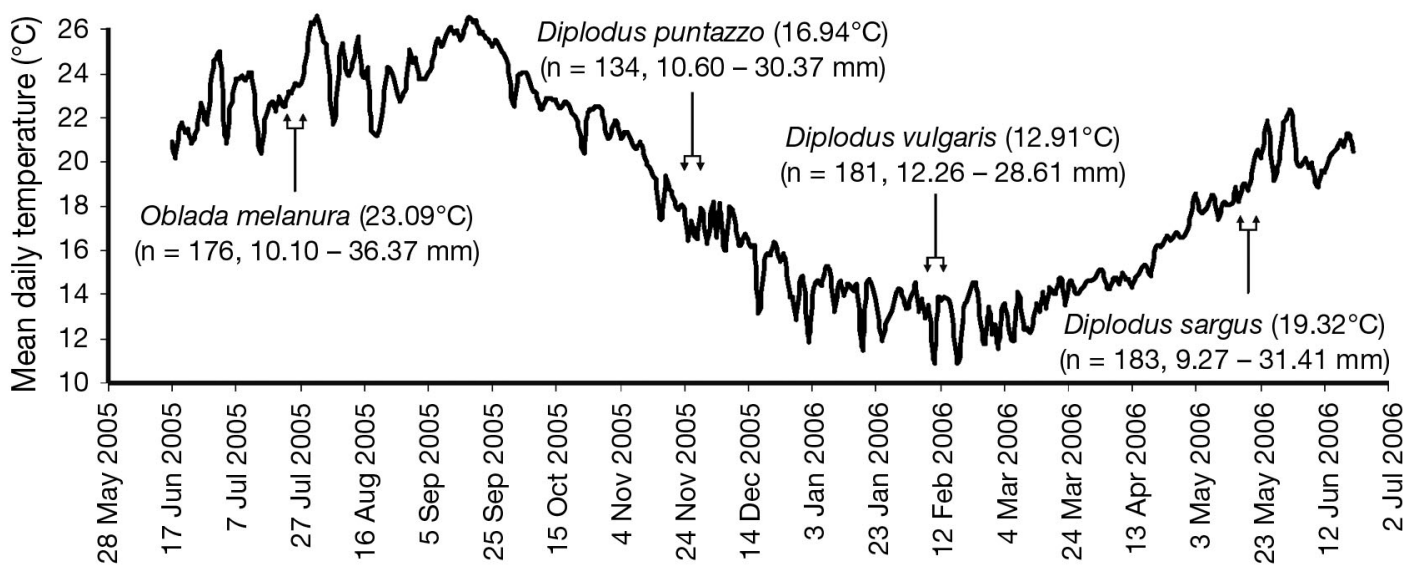

Fig. 1. Mean daily water temperature at the study area. Sampling dates (arrows) and the mean water temperature at the week of capture for each species is given (parentheses). The number of individuals caught as well as their standard length range are also given in parentheses 
At the sampling site, water temperature was recorded continuously at 15 min intervals by means of a submerged OMEGA Nomad OM-41 data logger enclosed in a waterproof case. The logger was set underwater (2 $\mathrm{m}$ depth) on 18 June 2005 and retrieved on 21 June 2006. The examined sparid species dominated the shallow $(<2 \mathrm{~m})$ waters of the study area in different seasons of the year under different temperature regimes (Fig. 1).

\section{Analysis of morphometric characters}

Seventeen morphometric characters were measured on each fish photograph: Standard Length (SL), Fork Length (FL), Pre-Orbital Length (SNL), Eye Diameter (EyeD), Head Length (HL), Pre-Dorsal Fin Length (PreDFL), Post-Dorsal Fin Length (PostDFL), Pre-Anal Fin Length (PreAFL), Post-Anal Fin Length (PostAFL), Pre-Pelvic Fin length (PrePlvFL), PreAnal Length (PreAL), Mid-Body Length (MidBL), Post-Anal Length (PostAL), Head Depth 1 (HD1), Head Depth 2 (HD2), Body Depth (BD) and Caudal peduncle Depth (CpD) (for further details see Nikolioudakis et al. 2010).

Patterns of multivariate allometry for each species were studied through Principal Component Analysis (PCA) of the covariance matrix of the log-transformed morphometric measurements (Jolicoeur 1963a,b, Shea 1985, Klingenberg \& Froese 1991). The point of change in oblique orientation of the second principal component (PC2) scores in relation to SL was estimated using a piece-wise linear regression (Fig. 2) and considered to define mean length-at-metamorphosis, $L_{\mathrm{m}}$ (morphometric characters). This methodology was developed and applied first to D. sargus (Nikolioudakis et al. 2010) based on the work of Shea (1985). According to the latter, in an ontogenetic series in which shifts in allometric growth patterns between sequential stages (different growth stanzas) exist, these shifts would be reflected in the multistage PCA as divergent PC2 trajectories (changes in oblique orientation) in relation to the PC1 (or SL).

Comparisons of multivariate allometric growth patterns of individual morphometric characters were carried out by plotting bootstrapped confidence intervals of allometric (PC1) coefficients and evaluating their departure from the theoretical value for multivariate isometry $1 / \sqrt{ } p$, where $p$ denotes the number of measured characters (Klingenberg \& Froese 1991). Multivariate allometry was compared for fish $<L_{\mathrm{m}}$ (Group 1) and fish $\geq L_{\mathrm{m}}$ (Group 2), both intra- and inter-specifically.

\section{Analysis of morphological characters}

The same set of characters examined in D. sargus (Nikolioudakis et al. 2010) were also studied in $O$. melanura, D. puntazzo and D. vulgaris (Table 1). This included 6 osteological characters, relating to fin calcification (proximal radials of each the dorsal, anal and pectoral fin [Prx], distal radials of the dorsal fin [Rd], epurals of the caudal fin [Ep], and basiptery-

\section{7 morphometric characters}
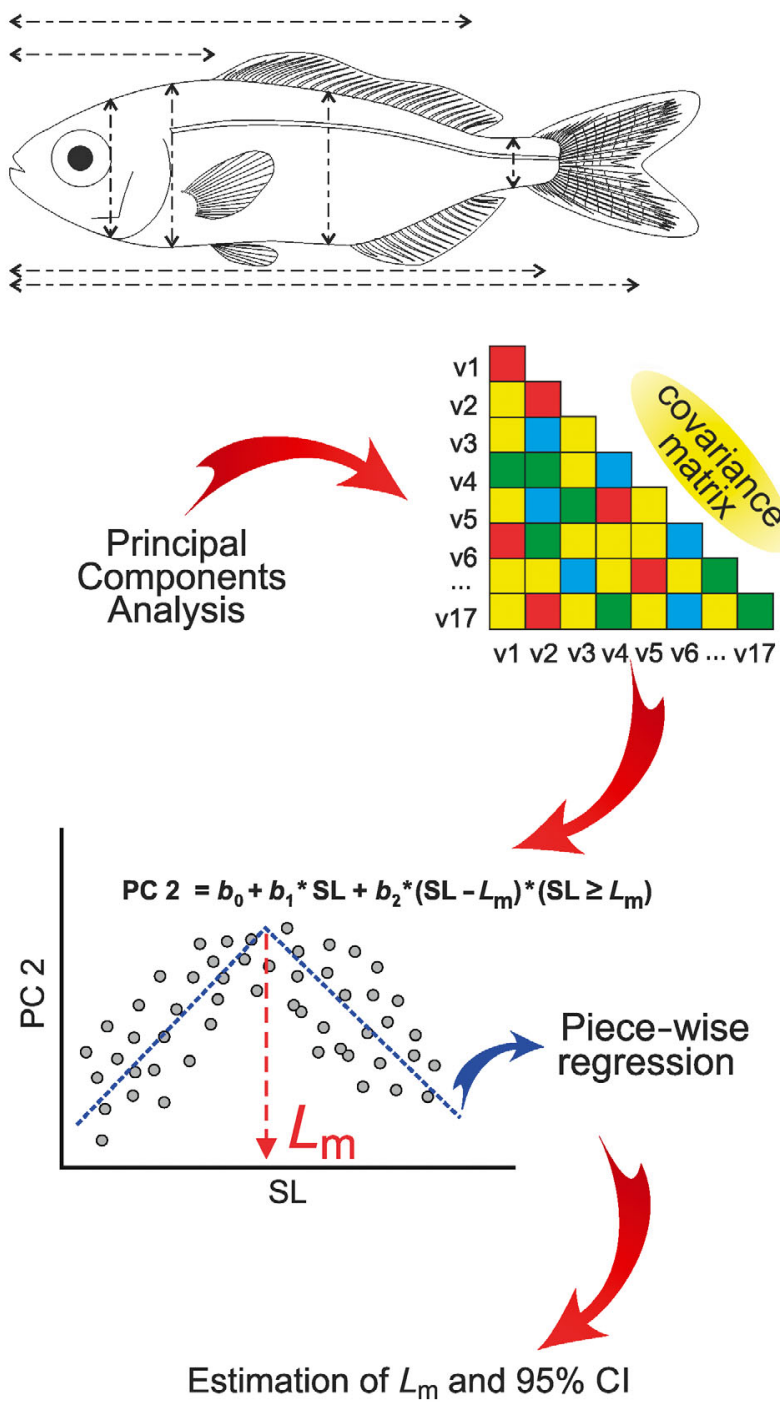

Fig. 2. Schematic of the steps adopted to define mean lengthat-metamorphosis $\left(L_{\mathrm{m}}\right)$ based on morphometry (Nikolioudakis et al. 2010). A Principal Component Analysis is performed on the covariance matrix of log-transformed morphometric measurements and a piece-wise regression is fitted on the PC2 versus SL relationship. $L_{\mathrm{m}}$ and its $95 \%$ confidence interval is estimated as the breakpoint of the piecewise regression 
Table 1. Morphological characters (external and osteological) and their states. S: Hard Spines, R: Lepidotrichia, SCR: Dermatotrichia, Ep: Epurals, Prx: Proximal radials, Rd: Distal radials, Bp: Basypterygium (see also Fig. 2 in Nikolioudakis et al. 2010). Characters marked with an asterisk were also examined but finally excluded from subsequent analyses as they had attained their definite number and were fully calcified in all specimens. Dermatotrichia of the caudal fin presented high variability in number to be useful in this study and were also excluded from analyses.

\begin{tabular}{|c|c|c|c|}
\hline \multirow{2}{*}{ Character } & & \multirow{2}{*}{ State $\frac{}{1}$} & \multirow[b]{2}{*}{2} \\
\hline & 0 & & \\
\hline \multicolumn{4}{|l|}{ External } \\
\hline Body coloration & $\begin{array}{l}\text { Melanophores } \\
\text { on the head and } \\
\text { abdomen. Two of } 3 \\
\text { may also be present on } \\
\text { the caudal peduncle }\end{array}$ & $\begin{array}{l}\text { Melanophores } \\
\text { expanding on } \\
\text { the sides of } \\
\text { body and tail }\end{array}$ & $\begin{array}{c}\text { Adult } \\
\text { pigmentation } \\
\text { pattern } \\
\text { completed }\end{array}$ \\
\hline Lateral line canal & Absent & Partially formed & Complete \\
\hline $\begin{array}{l}\text { Ventral region } \\
\text { scale coverage }\end{array}$ & Absent & Partial & Complete \\
\hline $\begin{array}{l}\text { Fish body scale } \\
\text { coverage }\end{array}$ & Absent & Partial & Complete \\
\hline $\begin{array}{l}\text { Osteological } \\
\text { Dorsal fin } \\
\left(\mathrm{S}^{*}, \mathrm{R}^{*}, \operatorname{Prx}, \mathrm{Rd}\right)\end{array}$ & Cartilaginous & Calcifying & Calcified \\
\hline $\begin{array}{l}\text { Anal fin } \\
\left(\mathrm{S}^{*}, \mathrm{R}^{*}, \operatorname{Prx}, \mathrm{Rd}\right)\end{array}$ & Cartilaginous & Calcifying & Calcified \\
\hline $\begin{array}{l}\text { Caudal fin } \\
\left(\mathrm{R}^{*}, \mathrm{SCR}^{*}, \mathrm{Ep}\right)\end{array}$ & Cartilaginous & Calcifying & Calcified \\
\hline $\begin{array}{l}\text { Pectoral fin } \\
\left(\mathrm{R}^{*}, \operatorname{Prx}, \mathrm{Rd}^{*}\right)\end{array}$ & Cartilaginous & Calcifying & Calcified \\
\hline $\begin{array}{l}\text { Pelvic fin } \\
\text { (Bp) }\end{array}$ & Cartilaginous & Calcifying & Calcified \\
\hline
\end{tabular}

gium of the pelvic fin [Bp]) and 4 characters related with external morphology (body coloration, lateral line canal, coverage of ventral body region with scales, coverage of fish body with scales). In each species, an ontogenetic series consisting of one randomly selected fish per $\sim 0.5 \mathrm{~mm} \mathrm{SL}$, covering the entire size range of sampled fish was examined $(O$. melanura: $\mathrm{n}=41, D$. puntazzo: $\mathrm{n}=33, D$. vulgaris: $\mathrm{n}=$ 25 , D. sargus: $\mathrm{n}=38$ ). The calcification state of osteological characters was assessed after staining the fish with Alizarin Red and Alcian Blue solutions (Park \& Kim 1984). Every studied morphological character was assigned equal weight, i.e. it had 3 possible states (0: larval, 1: intermediate, 2: juvenile) (Table 1). For body pigmentation pattern all specimens used in the morphometric analysis were scored. More details are provided in Nikolioudakis et al. (2010).

The mean length at state 1 (intermediate state) of each morphological character was calculated. Mean lengths were subsequently averaged and the resulting value and coefficient of variation (CV) were used to index 'mean length at morphological change',
$L_{\mathrm{m}}$ (morphological characters) and its variability, respectively.

$\mathrm{CV}$ of $L_{\mathrm{m}}$ can be considered as a measure of synchronization of changing characters during the transition from larval to juvenile sate, i.e. the higher the CV the lower the synchronization of examined characters.

For each morphological character, the length at which state 1 starts, ends as well as the respective range (end minus start) were determined. Furthermore, these lengths were expressed in terms of the ontogenetic index of Fuiman (1994):

$$
O_{\mathrm{L}}=100 \times \log L / \log L_{\mathrm{m}}
$$

where $O_{\mathrm{L}}$ is the ontogenetic index, a numerical representation of developmental state of a fish with length $L$ and $L_{\mathrm{m}}$ is the length at metamorphosis as defined from the analysis of multivariate allometry $L_{\mathrm{m}}$ (morphometric characters).

\section{RESULTS}

In total, 674 fish were caught during the settlement period of each species (Fig. 1). Each species settled during a different period of the year: Diplodus vulgaris in winter (low temperatures), Oblada melanura in summer (high temperatures), and D. sargus (Nikolioudakis et al. 2010) and D. puntazzo in spring and autumn, respectively (intermediate temperatures) (Fig. 1).

\section{Multivariate allometry}

The PCA of morphometric characters and the plots of PC2 scores against SL (Table 2, Fig. 3) revealed the significant $(\mathrm{p}<0.01)$ change in allometric growth (change in oblique orientation of PC2 scores) of $D$. vulgaris, O. melanura and D. puntazzo as has already been described for the sample of D. sargus (Nikolioudakis et al. 2010). The fit of piece-wise regressions estimated $L_{\mathrm{m}}$ at $17.97 \mathrm{~mm}$ for $O$. melanura, $14.46 \mathrm{~mm}$ for D. puntazzo and $14.82 \mathrm{~mm}$ for D. vulgaris (Table 2, Fig. 3). The change in slope $\left(b_{2}\right)$ was higher in $D$. vulgaris and estimated $L_{\mathrm{m}}$ was more precise (Table 2). The respective estimate for $D$. sargus was $14.46 \mathrm{~mm}$ with CV $=0.023$ (Nikolioudakis et al. 2010). 
Table 2. Estimated parameters of the fitted piece-wise regressions PC2 = cipal component, SL is the standard length, $b_{0}$ is the y-intercept, $b_{1}$ is the slope of the relationship during the 'larval' stage, $b_{2}$ is the change in the larval slope $\left(b_{1}\right)$ that results in the slope of the relationship during the 'juvenile' stage, and $L_{\mathrm{m}}$ is the SL at which slope changes (considered to denote the mean length-at-metamorphosis). CV: coefficient of variation

\begin{tabular}{|lccccc|}
\hline Species & $b_{0}$ & $b_{1}$ & $b_{2}$ & $L_{\mathrm{m}}(\mathrm{CV})$ & $\mathrm{r}^{2}$ \\
\hline Oblada melanura & -0.604 & 0.007 & -0.011 & $17.97(0.031)$ & 38.56 \\
Diplodus puntazzo & -0.640 & 0.014 & -0.016 & $14.46(0.028)$ & 21.12 \\
Diplodus vulgaris & -1.651 & 0.024 & -0.029 & $14.82(0.013)$ & 44.41 \\
\hline
\end{tabular}
$b_{0}+b_{1} \mathrm{SL}+b_{2}\left(\mathrm{SL}-L_{\mathrm{m}}\right)\left(\mathrm{SL} \geq L_{\mathrm{m}}\right)$, where PC2 is the score of the $2^{\text {nd }}$ prin-

The completion of formation of the lateral line canal and coverage of ventral region with scales took place over very short length intervals whereas complete squamation was more prolonged in terms of size range (Table 3, see also Nikolioudakis et al. 2010 for D. sargus). Prolonged completion was also noticed for the osteological characters examined (Table 3). The overall mean length at character state 1 for the 10 characters considered was $15.75 \mathrm{~mm}$ for $O$. melanura, $14.23 \mathrm{~mm}$ for D. puntazzo and

The comparison of allometric vectors (PC1 coefficients) between groups (Group 1: fish $<L_{\mathrm{m}}$ and Group 2: fish $\geq L_{\mathrm{m}}$ ) (Fig. 4) revealed that, in general, D. puntazzo and $D$. vulgaris exhibited patterns similar to that described for $D$. sargus (Nikolioudakis et al. 2010). Inter-specific differences for fish $<L_{\mathrm{m}}$ and fish $\geq L_{\mathrm{m}}$, including $D$. sargus analyzed in Nikolioudakis et al. (2010), are illustrated in Figs. $5 \& 6$. Characters related to the horizontal axis of the body, and, more specifically, to general somatic length and tail length (SL, FL, PostDFL, PostAFL, PreAFL and PostAL), exhibited negative allometry that was more pronounced in Group 1 (Figs. 4 \& 5). In Group 2, the respective coefficients were, generally, closer to isometry (Figs. 4 \& 6). Measurements of the middle part of the body (HD2, BD, PreAL and MidBL) exhibited positive allometry in both groups (though slightly lower in Group 2). Characters of the cephalic region (HL, EyeD, SNL, HD1, PreDFL and PrePlvFL) were more or less isometric in both groups. A contrasting difference was observed in snout length (SNL) of D. puntazzo that turned from positive (Group 1) to negative allometry (Group 2). Finally, the depth at the caudal peduncle (CpD) grew isometrically in both groups. Regarding $O$. melanura, individual morphometric characters had similar patterns to those of Diplodus but with allometric coefficients closer to isometry. The 2 genera differed mainly with respect to characters of the cephalic region that were negatively allometric in $O$. melanura Group 2.

The acquisition of adult coloration ('juvenile pattern') in $O$. melanura was attained at approximately $L_{\mathrm{m}}$ (morphometric characters), whereas $D$. puntazzo and $D$. vulgaris exhibited intermediate pigmentation patterns, i.e. that between transparency of body flanks ('larval pattern') and adult pigmentation ('juvenile pattern'), at estimated $L_{\mathrm{m}}$ (Fig. 3).

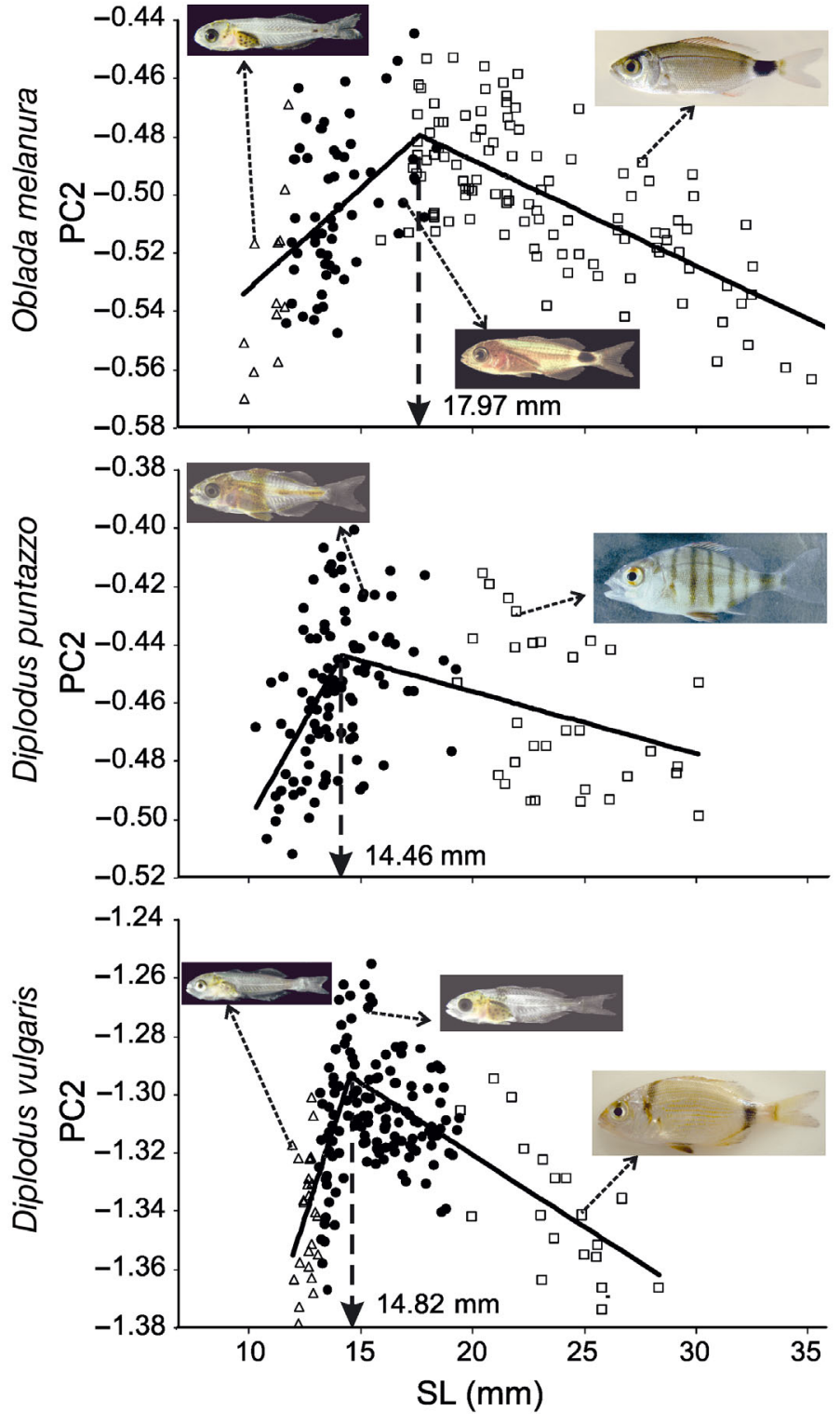

Fig. 3. Estimation of mean length-at-metamorphosis using morphometric characters. Fitted piece-wise regressions of PC2 scoreson-standard length (SL). Pigmentation state of individuals is also indicated. $\Delta$ : larval, $\bullet$ : intermediate, and $\square$ : juvenile 


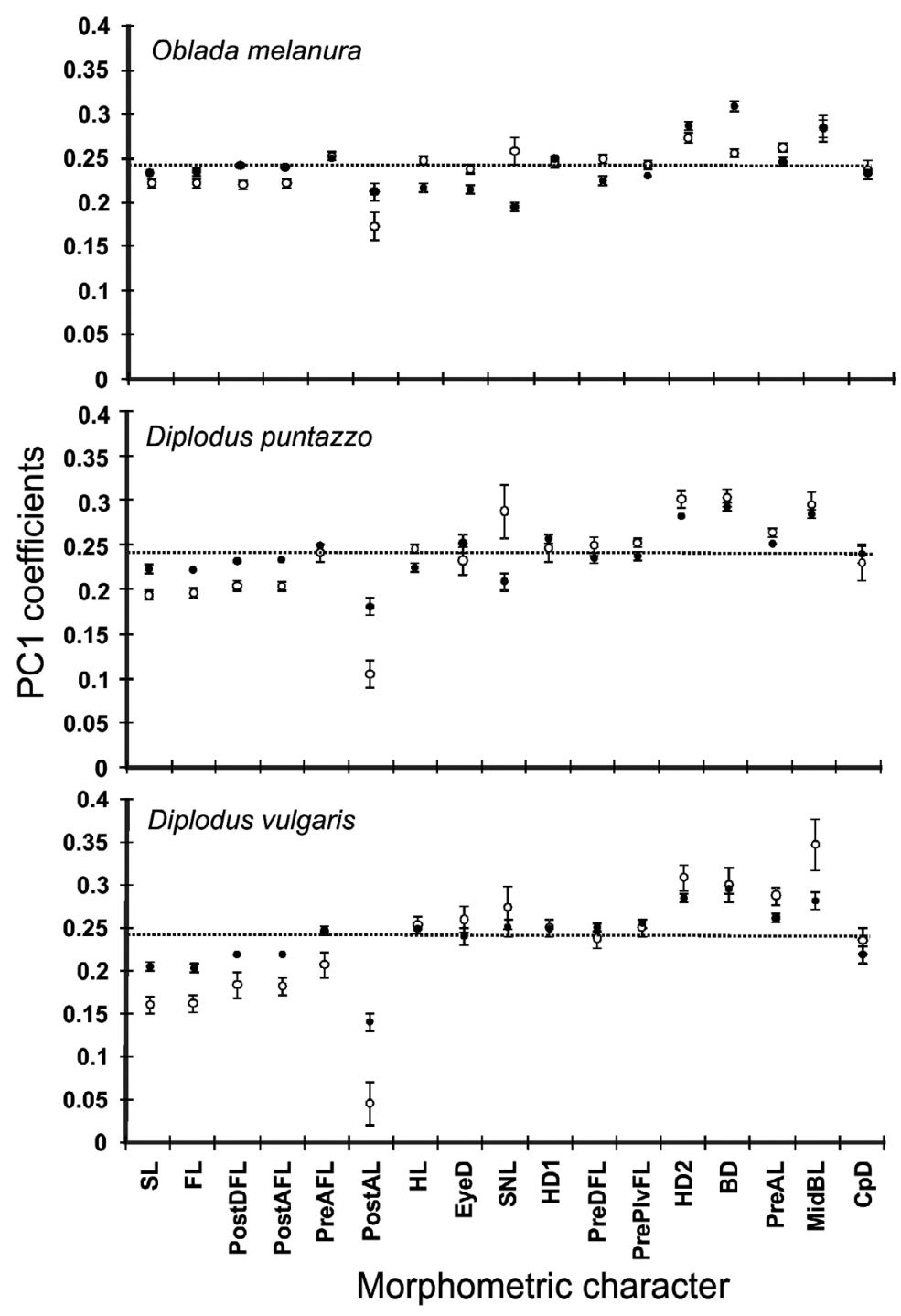

Fig. 4. Intraspecific comparisons. Allometric coefficients for morphometric characters for Group 1 (०) and Group $2(\bullet)$. Dashed lines indicate multivariate isometry (0.242). Error bars: $95 \%$ bootstrapped confidence intervals. SL: Standard Length, FL: Fork Length, SNL: PreOrbital Length, EyeD: Eye Diameter, HL: Head Length, PreDFL: PreDorsal Fin Length, PostDFL: Post-Dorsal Fin Length, PreAFL: Pre-Anal Fin Length, PostAFL: Post-Anal Fin Length, PrePlvFL: Pre-Pelvic Fin length, PreAL: Pre-Anal Length, MidBL: Mid-Body Length, PostAL: Post-Anal Length, HD1: Head Depth 1, HD2: Head Depth 2, BD: Body Depth, CpD: Caudal peduncle Depth

$16.17 \mathrm{~mm}$ for $D$. vulgaris (Table 3 ). The respective length for Diplodus sargus was $14.42 \mathrm{~mm}$ with $\mathrm{CV}=$ 0.092 (Nikolioudakis et al. 2010).

\section{Matching of changes during metamorphosis}

A comparison of $L_{\mathrm{m}}$ (morphometric characters), with the overall mean length at morphological change, i.e. mean length at character state $1 L_{\mathrm{m}}$ (mor- phological characters), demonstrates a close match between the $2 L_{\mathrm{m}} \mathrm{s}$ for $D$. puntazzo and D. sargus (Fig. 7A). $L_{\mathrm{m}}$ (morphological characters) was lower for $O$. melanura (summer) and larger in D. vulgaris (winter) (Fig. 7A). The $\mathrm{CV}$ of $L_{\mathrm{m}}$ (morphological characters) was negatively related to the $\mathrm{CV}$ from morphometric characters (Fig. 7B).

Considering $L_{\mathrm{m}}$ (morphometric characters) as being length-at-metamorphosis, no relationship was found between ontogenetic start $\left(O_{\mathrm{L}}\right.$ start) and ontogenetic end $\left(O_{\mathrm{L}}\right.$ end) (Table 4$)$. However, a significant negative relationship existed between $O_{\mathrm{L}}$ start and 'ontogenetic range' (i.e. $O_{\mathrm{L}}$ end minus $O_{\mathrm{L}}$ start) in each species separately or after pooling all data (Table 5). These relationships indicate that the closer a morphological character starts to change in relation to the allometric change the shorter the developmental time needed to complete transformation (acquisition of 'juvenile' state). $O$. melanura displayed the strongest correlation, $D$. vulgaris the weakest, and the remainding species intermediate correlation between $O_{\mathrm{L}}$ start and ontogenetic range (Table 5). ANCOVA models showed that the slopes of the relationships were homogeneous $(F=2.01, \mathrm{p}=0.133)$ but intercepts were statistically different between species $(F=10.36, \mathrm{p}<$ 0.001 ), indicating that the overall morphological change in $D$. vulgaris (winter) was late and in $O$. melanura early with regard to allometric change (Fig. 8).

\section{DISCUSSION}

Understanding ontogenetic transitions, especially those that are critical for the life of fish, is of prime importance in our attempt to determine factors that affect survival probabilities and control recruitment levels. Changes in form reflect changes in function and habitat (Fuiman 2002), however, the importance of morphological development and the ways that the latter is affected by external factors like temperature are often overlooked in ecological studies. The latter usually consider fish performance as a function of size or in poorly defined ontogenetic intervals (Somarakis \& Nikolioudakis 2010).

As discussed recently (Nikolioudakis et al. 2010 and references therein), multi-character approaches are very useful in delimiting ontogenetic intervals in 


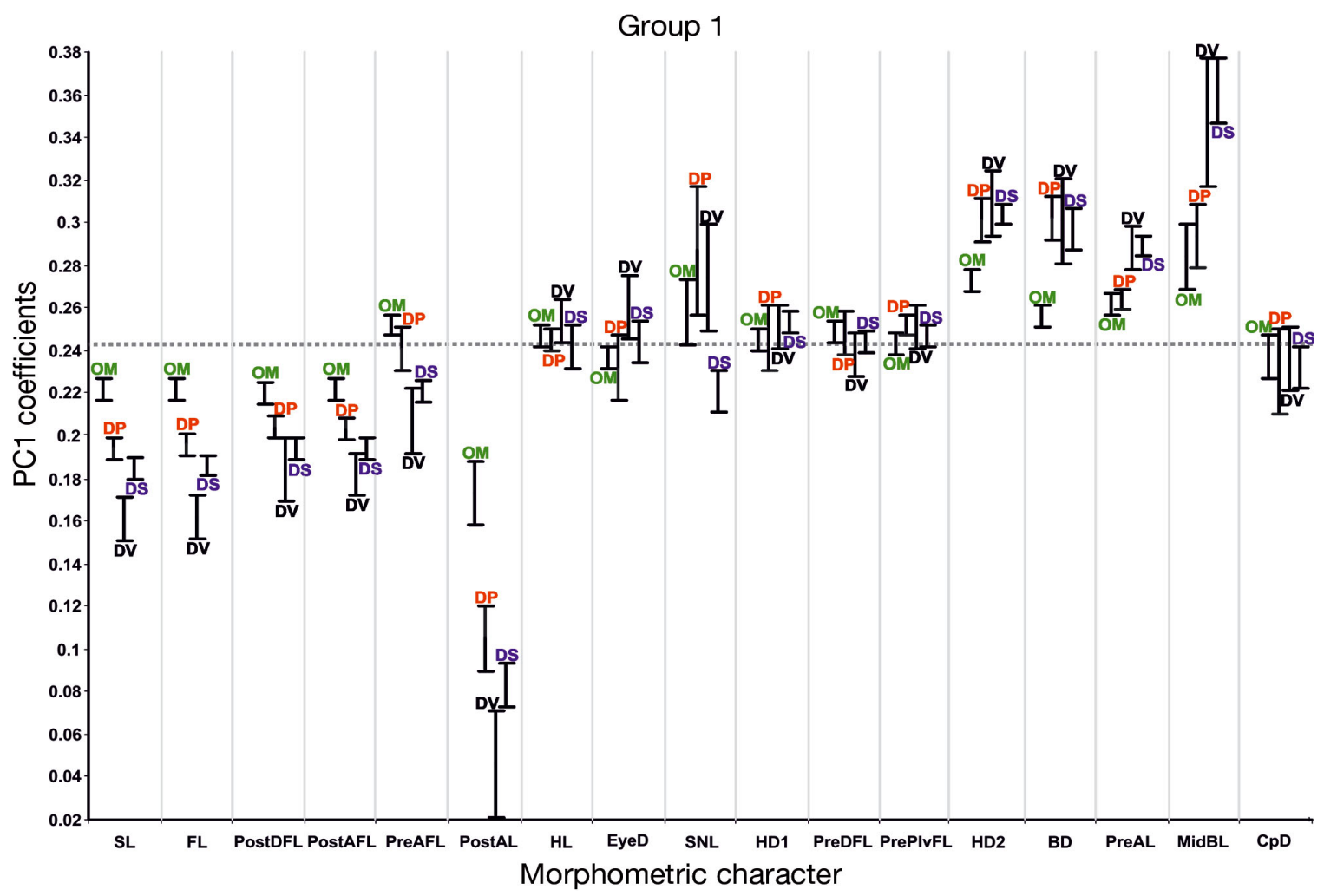

Fig. 5. Interspecific comparison of allometric coefficients for Group 1 (fish $<L_{\mathrm{m}}$ ). Dashed line indicates multivariate isometry (0.242). Error bars: $95 \%$ bootstrapped confidence intervals. OM: Oblada melanura, DP: Diplodus puntazzo, DV: D. vulgaris, DS: D. sargus. See Fig. 4 for abbreviations. D. sargus data are from Nikolioudakis et al. (2010)

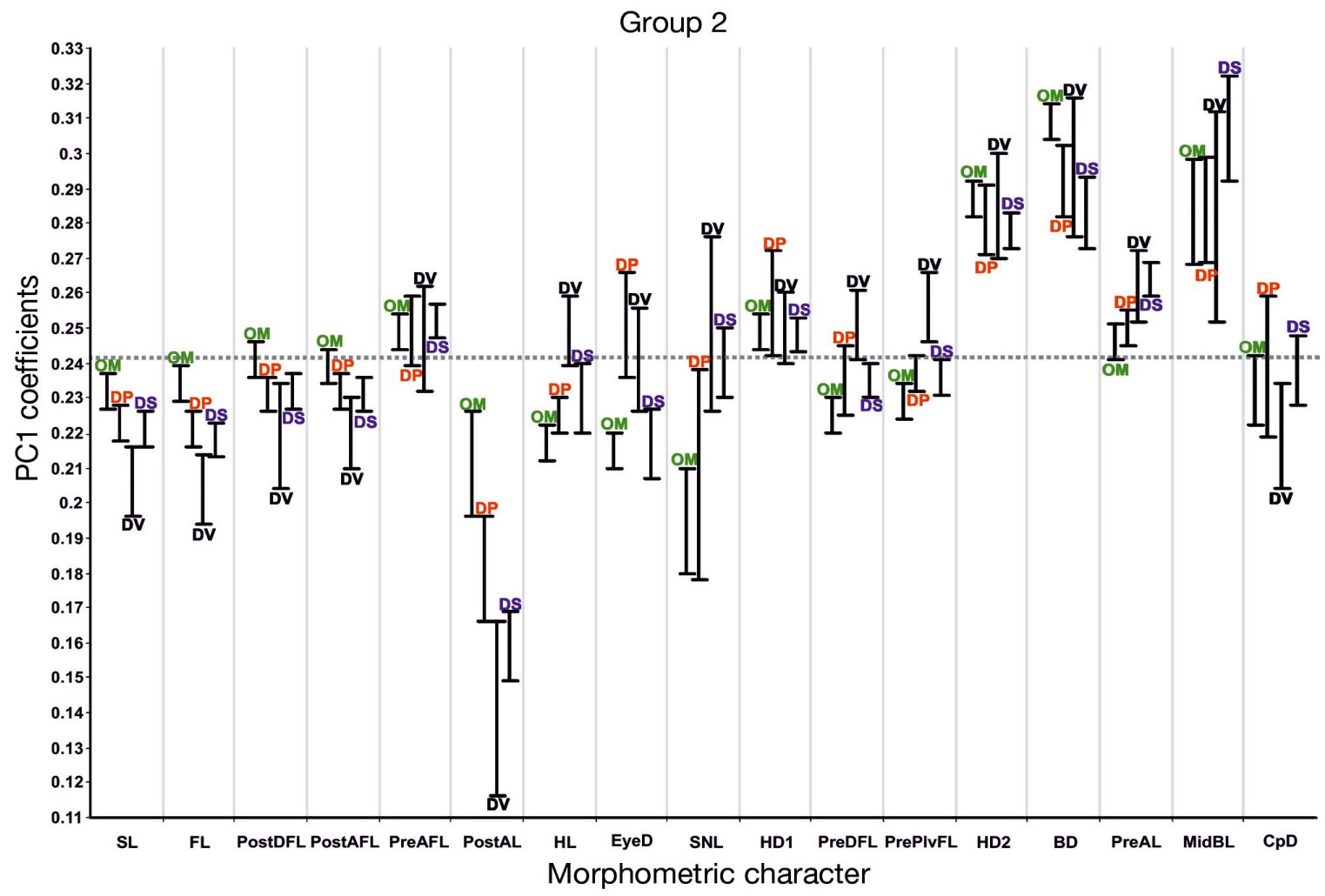

Fig. 6. Interspecific comparison of allometric coefficients for Group 2 (fish $\geq L_{\mathrm{m}}$ ). Dashed line indicates multivariate isometry (0.242). Error bars: $95 \%$ bootstrapped confidence intervals. OM: Oblada melanura, DP: Diplodus puntazzo, DV: D. vulgaris, DS: D. sargus. See Fig. 4 for abbreviations. D. sargus data are from Nikolioudakis et al. (2010) 
Table 3. Morphological characters. Start: minimum length for state 1. End: minimum length for state 2. Mean: mean length of fish in state 1. Range: End-Start. n: number of specimens observed in state 1 for the respective character. Abbreviations of the osteological characters listed are given in Table 1. For the overall mean of each species CVs are also given in parentheses

\begin{tabular}{|c|c|c|c|c|c|c|c|c|c|c|c|c|c|c|c|}
\hline \multirow[t]{2}{*}{ Morphological character } & \multicolumn{5}{|c|}{ Oblada melanura } & \multicolumn{5}{|c|}{ Diplodus puntazzo } & \multicolumn{5}{|c|}{ Diplodus vulgaris } \\
\hline & Start & End & Mean & Range & $\mathrm{n}$ & Start & End & Mean & Range & $\mathrm{n}$ & Start & End & Mean & Range & $\mathrm{n}$ \\
\hline Dorsal fin Rd & 12.50 & 18.04 & 15.06 & 5.53 & 11 & 12.51 & 16.43 & 14.26 & 3.92 & 8 & 12.99 & 17.04 & 14.76 & 4.05 & 8 \\
\hline Dorsal fin Prx & 12.50 & 21.05 & 16.56 & 8.55 & 17 & 11.53 & 15.49 & 13.27 & 3.96 & 8 & 11.99 & 16.07 & 13.75 & 4.08 & 8 \\
\hline Anal fin Prx & 11.52 & 20.04 & 15.56 & 8.52 & 17 & 11.06 & 17.85 & 14.02 & 6.79 & 13 & 11.59 & 18.03 & 14.51 & 6.44 & 13 \\
\hline Caudal fin Ep & 13.51 & 18.50 & 15.80 & 4.99 & 10 & 15.00 & 17.85 & 16.01 & 2.84 & 5 & 15.48 & 18.52 & 16.77 & 3.05 & 6 \\
\hline Pectoral fin Prx & 11.52 & 19.62 & 15.31 & 8.10 & 16 & 11.06 & 19.16 & 14.58 & 8.10 & 15 & 11.59 & 18.52 & 14.77 & 6.94 & 14 \\
\hline Pelvic fin Bp & 11.52 & 18.50 & 14.80 & 6.98 & 14 & 11.06 & 15.49 & 13.02 & 4.43 & 9 & 11.59 & 18.52 & 14.77 & 6.94 & 14 \\
\hline Body coloration & 12.01 & 17.50 & 14.56 & 5.49 & 11 & 10.53 & 19.16 & 14.32 & 8.63 & 16 & 13.49 & 19.87 & 16.51 & 6.37 & 13 \\
\hline Ventral region scale coverage & 15.98 & 17.50 & 16.56 & 1.53 & 3 & 13.50 & 15.00 & 14.01 & 1.51 & 3 & 19.00 & 19.52 & 19.00 & 0.52 & 1 \\
\hline Fish body scale coverage & 14.54 & 20.48 & 17.32 & 5.94 & 12 & 13.03 & 17.11 & 14.75 & 4.08 & 8 & 17.04 & 24.94 & 18.80 & 7.90 & 8 \\
\hline Lateral line canal & 15.98 & 16.71 & 15.98 & 0.73 & 1 & 14.03 & 14.51 & 14.03 & 0.48 & 1 & 18.03 & 18.52 & 18.03 & 0.50 & 1 \\
\hline Average & 13.16 & 18.79 & $\begin{array}{c}15.75 \\
(0.055)\end{array}$ & 5.64 & & 12.33 & 16.80 & $\begin{array}{c}14.23 \\
(0.058)\end{array}$ & 4.47 & & 14.28 & 18.96 & $\begin{array}{c}16.17 \\
(0.119)\end{array}$ & 4.68 & \\
\hline
\end{tabular}

the sense that they can effectively capture 'synchronization', a condition necessary for defining thresholds (Ková et al. 1999). In the present study, we provide evidence that synchronization of changes in the same subsets of morphological and morphometric characters vary largely between the 4, closelyrelated sparid species, both among the same set of characters (as indexed by the CV of $L_{\mathrm{m}}$ ) and between the morphological and morphometric subsets (differences in mean $L_{\mathrm{m}}$ ).

$L_{\mathrm{m}}$, as defined by morphometric and morphological characters, was similar for the species developing at intermediate temperatures in spring and autumn, namely Diplodus sargus and D. puntazzo. In contrast, $L_{\mathrm{m}}$ (morphological characters) was smaller than $L_{\mathrm{m}}$ (morphometric characters) for Oblada melanura, developing in warm waters during summer, and higher for $D$. vulgaris, developing in cold waters during winter. $L_{\mathrm{m}}$ (morphometric characters), however, was almost identical for the 3 species of Diplodus, indicating that size of metamorphotic changes in allometry is less dependent on temperature than morphological change, mostly reflecting evolutionary relatedness (i.e. congeneric species had similar $\left.L_{\mathrm{m}} \mathrm{s}\right)$. In that sense, $L_{\mathrm{m}}$ (morphological characters) seems highly dependent on temperature and can be
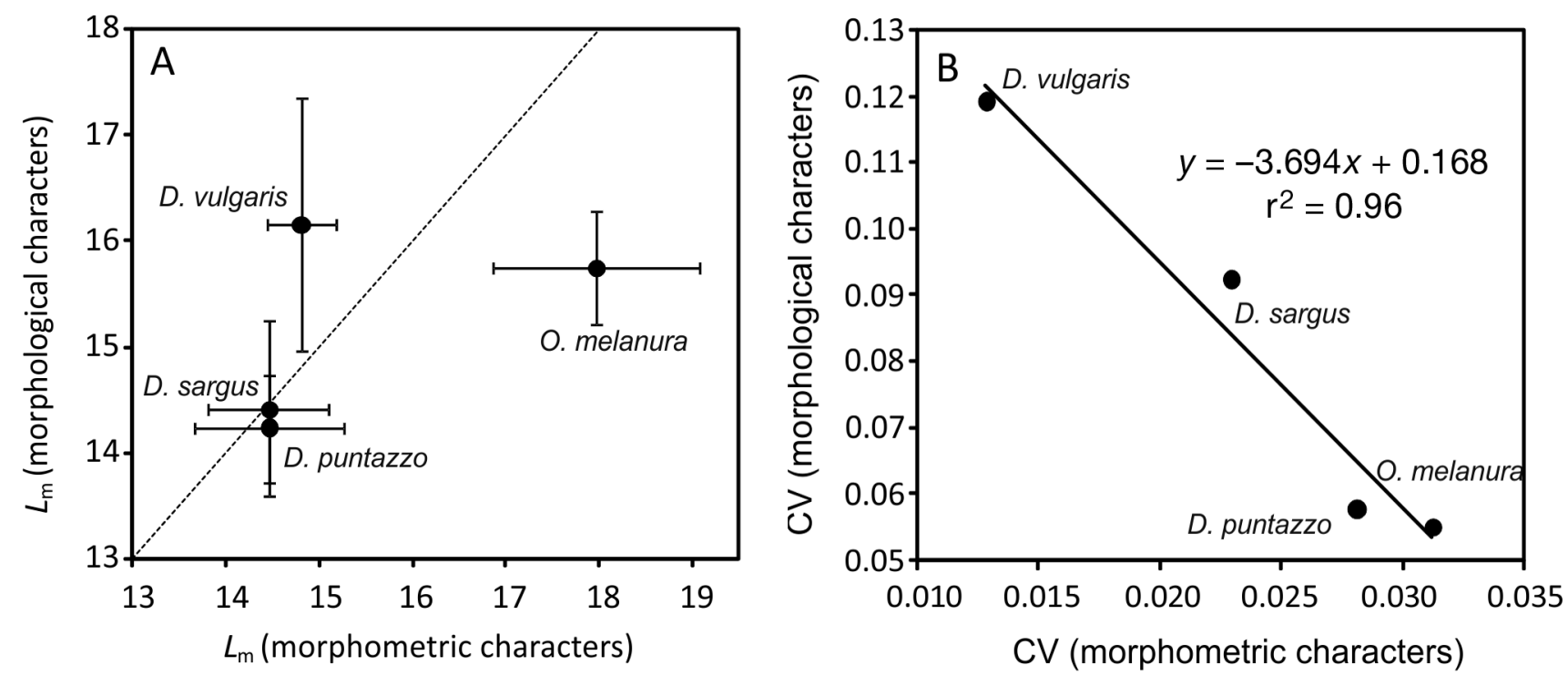

Fig. 7. Comparison between mean morphological and mean morphometric change in the 4 sparid species (see Fig. 6). (A) Plot of the mean length-at-metamorphosis $\left(L_{\mathrm{m}}\right)$ for morphological vs. morphometric characters. Error bars: $95 \%$ confidence intervals. Dashed line is $y=x$. (B) Relationship between coefficients of variation (CVs) for morphological vs. morphometric estimates of $L_{\mathrm{m}}$. D. sargus data are from Nikolioudakis et al. (2010) 
Table 4. Ontogenetic start $\left(O_{\mathrm{L}}\right.$ start) and ontogenetic end $\left(O_{\mathrm{L}}\right.$ end) for character state 1 , based on the ontogenetic index of Fuiman (Fuiman 1994) with lengths-at-metamorphosis as defined by the analysis of morphometric characters. See Table 1 for abbreviations. D. sargus data are from Nikolioudakis et al. (2010)

\begin{tabular}{|c|c|c|c|c|c|c|c|c|c|c|}
\hline \multirow[t]{2}{*}{ Morphological character } & \multicolumn{2}{|c|}{ O. melanura } & \multicolumn{2}{|c|}{ D. puntazzo } & \multicolumn{2}{|c|}{ D. vulgaris } & \multicolumn{2}{|c|}{ D. sargus } & \multicolumn{2}{|c|}{ Average } \\
\hline & $O_{\mathrm{L}}$ start & $O_{\mathrm{L}}$ end & $O_{\mathrm{L}}$ start & $O_{\mathrm{L}}$ end & $O_{\mathrm{L}}$ start & $O_{\mathrm{L}}$ end & $O_{\mathrm{L}}$ start & $O_{\mathrm{L}}$ end & $O_{\mathrm{L}}$ start & $O_{\mathrm{L}}$ end \\
\hline Dorsal fin Rd & 87.44 & 100.13 & 94.57 & 104.78 & 95.11 & 105.18 & 89.87 & 111.19 & 91.75 & 105.32 \\
\hline Dorsal fin Prx & 87.44 & 105.48 & 91.51 & 102.57 & 92.15 & 103.00 & 89.87 & 100.30 & 90.24 & 102.84 \\
\hline Anal fin Prx & 84.61 & 103.77 & 89.96 & 107.88 & 90.87 & 107.26 & 86.18 & 108.75 & 87.90 & 106.91 \\
\hline Caudal fin Ep & 90.13 & 101.00 & 101.38 & 107.88 & 101.61 & 108.27 & 93.06 & 103.57 & 96.54 & 105.18 \\
\hline Pectoral fin Prx & 84.61 & 103.04 & 89.96 & 110.53 & 90.87 & 108.27 & 86.18 & 107.25 & 87.90 & 107.28 \\
\hline Pelvic fin $\mathrm{Bp}$ & 84.61 & 101.00 & 89.96 & 102.57 & 90.87 & 108.27 & 86.18 & 102.56 & 87.90 & 103.60 \\
\hline Body coloration & 86.06 & 99.09 & 88.12 & 110.53 & 96.52 & 110.87 & 94.58 & 112.25 & 91.32 & 108.19 \\
\hline Ventral region scale coverage & 95.93 & 99.09 & 97.42 & 101.38 & 109.22 & 110.22 & 102.56 & 104.98 & 101.28 & 103.92 \\
\hline Fish body scale coverage & 92.66 & 104.52 & 96.09 & 106.30 & 105.18 & 119.31 & 98.87 & 107.25 & 98.20 & 109.35 \\
\hline Lateral line canal & 95.93 & 97.48 & 98.87 & 100.13 & 107.26 & 108.27 & 102.56 & 104.98 & 101.16 & 102.72 \\
\hline
\end{tabular}

Table 5. Results of the linear regressions of $\left(O_{\mathrm{L}}\right.$ start)-on$\left[\left(O_{\mathrm{L}}\right.\right.$ end $)-\left(O_{\mathrm{L}}\right.$ start $\left.)\right]$ and $\left(O_{\mathrm{L}}\right.$ end $)$-on- $\left[\left(O_{\mathrm{L}}\right.\right.$ end $)-\left(O_{\mathrm{L}}\right.$ start $\left.)\right]$. ns: non-significant. $D$. sargus data are from Nikolioudakis et al. (2010)

\begin{tabular}{|cccccc|}
\hline Species & Slope & Intercept & $\mathrm{r}^{2}$ & $\mathrm{p}$ \\
\hline$O_{\mathrm{L}}$ start & Oblada melanura & -0.68 & 97.43 & 0.83 & $<0.01$ \\
& Diplodus puntazzo & -0.57 & 100.40 & 0.73 & $<0.01$ \\
& Diplodus vulgaris & -0.94 & 108.20 & 0.61 & $<0.01$ \\
& Diplodus sargus & -0.74 & 102.88 & 0.72 & $<0.01$ \\
& All species & -0.76 & 102.60 & 0.59 & $<0.01$ \\
$O_{\mathrm{L}}$ end & Oblada melanura & 0.32 & 97.42 & 0.50 & $<0.05$ \\
& Diplodus puntazzo & 0.43 & 100.40 & 0.60 & $<0.01$ \\
& Diplodus vulgaris & & & & $\mathrm{ns}$ \\
& Diplodus sargus & & & & $\mathrm{ns}$ \\
& All species & 0.24 & 102.60 & 0.13 & $<0.05$ \\
\hline
\end{tabular}

considered less suitable for defining mean size-atmetamorphosis. Temperature dependence of developmental rates and smaller sizes at character or interval change have been reported for numerous fish species as well as between cold and warm water species (e.g. Brevoortia tyrannus and Sciaenops ocel-

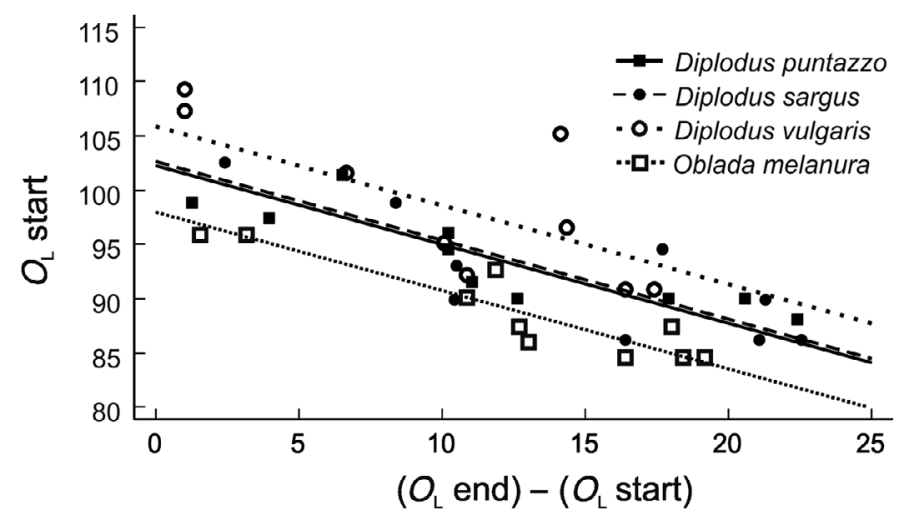

Fig. 8. Plot of the fitted ANCOVA model for the morpho-logical characters of the 4 species. $D$. sargus data are from Nikolioudakis et al. (2010) latus [Fuiman et al. 1998], Dicentrarchus labrax [Koumoundouros et al. 2001], Pagellus erythrinus [Sfakaniakis et al. 2004], Danio rerio [Parichy et al. 2009], Clupea harengus [Johnston \& Temple 2002], Gadus morhua [Jordaan et al. 2006]).

Considering that $L_{\mathrm{m}}$ (morphometric characters) better expresses the size at metamorphosis, and comparing ontogenetic 'timing' $\left(O_{\mathrm{L}}\right.$ start) (sensu Fuiman, $1994)$ versus 'duration' of transition $\left(O_{\mathrm{L}}\right.$ end $-O_{\mathrm{L}}$ start) for the different morphological characters examined here, a negative linear relationship emerged, implying that the later a morphological change occurs with regard to timing of allometric change, the shorter is its ontogenetic range (i.e. it is more abrupt). The slope of the relationship was not significantly different between the 4 species but the intercept was higher for $D$. vulgaris and lower for O. melanura, indicating that, besides the aforementioned differences in overall timing of morphological transition, ontogenetic range (abruptness of change) of individual morphological characters was generally independent of species (temperature). However, the strength of the relationship ( $\mathrm{r}^{2}$ in Table 5) was higher for $O$. melanura, intermediate for $D$. puntazzo and $D$. sargus, and lower for $D$. vulgaris, implying that decreasing temperature induces increasing variability in morphological change, i.e. the change is less synchronized between characters. The negative relationship (Fig. 7B) between variability in allometric change and morphological transformation highlights a yet unknown aspect of ontogenetic thresholds. Synchronization of allometric change of mensural characters might be higher at low temperatures but that of morphological characters higher at high temperatures.

Relative allometric growth patterns of most morphometric characters examined here were generally 
similar for the 3 species of Diplodus ( $D$. puntazzo and $D$. vulgaris: this study, D. sargus: Nikolioudakis et al. 2010, see also Vigliola \& Harmelin-Vivien 2001 and Loy et al. 2001, as well as for O. melanura). The PC1 coefficients of most characters of fish with $\mathrm{SL} \geq L_{\mathrm{m}}$ (Group 2) always exhibited values closer to isometry, indicating a transition from intense allometric (larval) to isometric growth (juvenile). Occasionally, there were certain species-specific patterns such as the strong contrast of snout (SNL) allometry in $D$. puntazzo, which possesses a pointed head in its metamorphosed stage (Loy et al. 2001). The positive and negative allometric patterns of the middle and posterior part of the body, respectively, are associated with changes in body form related to requirements of the benthic life. The profiles of the middle part of the body were always found to deepen, something that is necessary for maneuvering (quick starts and rapid turns) (Webb 1984). Furthermore, pronounced growth in the abdominal region (MidBL) implies enhanced development of the intestine (Elbal et al. 2004), a finding similar to other studies that have shown that the middle part of the body increases later throughout ontogeny (after head and tail) in bilateral species (Osse et al. 1997, van Snik et al. 1997, Gozlan et al. 1999), as opposed to asymmetrical species (Paralichthys californicus, Gisbert et al. 2002).

In summary, the use of standard multivariate protocols to compare allometric and morphological changes associated with metamorphosis highlighted the relative importance of taxonomic relatedness and season (temperature) in determining the size at metamorphosis and the degree of synchronization (abruptness of change) both within and between mensural and morphological characters. The results obtained have implications for current views of ontogenetic processes and life history theory (Copp et al. 1999) and warrant further investigations under controlled laboratory conditions.

Acknowledgements. We thank the European Social Fund (ESF), Operational Program for Educational and Vocational Training II (EPEAEK II), and particularly the Program PYTHAGORAS II, for funding this work. The authors thank S. Kyparissis, E. Schismenou, S. Isari and A. Ramfos for their assistance in field sampling and laboratory analysis, and E. Georgakopoulou for her help with fish staining. We would also thank the 4 anonymous reviewers for improving our manuscript.

\section{LITERATURE CITED}

Ben Khemis I, Gisbert E, Alcaraz C, Zouiten D and others (2013) Allometric growth patterns and development in larvae and juveniles of thick-lipped grey mullet Chelon labrosus reared in mesocosm conditions. Aquacult Res 44:1872-1888

> Copp GH, Kováč V (1996) When do fish with indirect development become juveniles? Can J Fish Aquat Sci 53: 746-752

Copp GH, Kováč V, Hensel K(1999) Prelude: looking at early development in fishes. Environ Biol Fish 56:7-14

Ditty JG, Fuiman LA, Shaw RF (2003) Characterizing natural intervals of development in fishes: an example using blennies (Teleostei: Blenniidae). In: Browman HI, Skiftesvik $A B$ (eds) The big fish bang. Proc 26th Ann Larval Fish Conference. Institute of Marine Research, Bergen, p 405-418

Elbal MT, García Hernández MP, Lozano MT, Agulleiro B (2004) Development of the digestive tract of gilthead sea bream (Sparus aurata, L.). Light and electron microscopic studies. Aquaculture 234:215-238

Fuiman LA (1994) The interplay of ontogeny and scaling in the interactions of fish larvae and their predators. J Fish Biol 45(Suppl A):55-79

Fuiman LA (2002) Special considerations of fish eggs and larvae. In: Fuiman LA, Werger RG (eds) Fishery science: the unique contributions of early life stages. Blackwell Science, Oxford, p 1-32

Fuiman LA, Poling KR, Higgs DM (1998) Quantifying developmental progress for comparative studies of larval fishes. Copeia 1998:602-611

> García-Rubies A, Macpherson E (1995) Substrate use and temporal pattern of recruitment in juvenile fishes of the Mediterranean littoral. Mar Biol 124:35-42

Gisbert E, Merino G, Muguet JB, Bush D, Piedrahita RH, Conklin DE (2002) Morphological development and allometric growth patterns in hatchery-reared California halibut larvae. J Fish Biol 61:1217-1229

Gozlan RE, Copp GH, Tourenq JN (1999) Comparison of growth plasticity in the laboratory and field, and implications for the onset of juvenile development in sofie, Chondrostoma toxostoma. Environ Biol Fish 56:153-165

Higgs DM, Fuiman LA (1998) Associations between sensory development and ecology in three species of clupeoid fish. Copeia 1998:133-144

Johnston IA, Temple GK (2002) Thermal plasticity of skeletal muscle phenotype in ectothermic vertebrates and its significance for locomotory behaviour. J Exp Biol 205: 2305-2322

Jolicoeur P (1963a) The multivariate generalization of the allometry equation. Biometrics 19:497-499

Jolicoeur P (1963b) The degree of generality of robustness in Martes americana. Growth 27:1-27

> Jordaan A, Hayhurst SE, Kling LJ (2006) The influence of temperature on the stage at hatch of laboratory reared Gadus morhua and implications for comparisons of length and morphology. J Fish Biol 68:7-24

Kiparissis S, Tserpes G, Somarakis S, Economidis S, Koutsikopoulos C (2008) Site-attachment behaviour of Oblada melanura (Linnaeus, 1758) (Osteichthyes: Sparidae) benthic larvae: a quantitative approach. Sci Mar 72:429-436

> Klingenberg CP, Froese R (1991) A multivariate comparison of allometric growth patterns. Syst Zool 40:410-419

> Koumoundouros G, Divanach P, Anezaki L, Kentouri M (2001) Temperature-induced ontogenetic plasticity in sea bass (Dicentrarchus labrax). Mar Biol 139:817-830

Koumoundouros G, Ashton C, Giopanou I, Ksenikoudakis G, Georgakopoulou E, Stickland NC (2009) Ontogenetic differentiation of swimming performance in gilthead sea 
bream (Sparus aurata, Linnaeus 1758) during metamorphosis. J Exp Mar Biol Ecol 370:75-81

Kováč V, Copp GH, Francis MP (1999) Morphometry of the stone loach, Barbatula barbatula: Do mensural characters reflect the species' life history thresholds? Environ Biol Fish 56:105-115

Loy A, Bertelletti M, Costa C, Ferlin L, Cataudella S (2001) Shape changes and growth trajectories in the early stages of three species of the genus Diplodus (Perciformes, Sparidae). J Morphol 250:24-33

McCormick MI, Makey L, Dufour V (2002) Comparative study of metamorphosis in tropical reef fishes. Mar Biol 141:841-853

Nikolioudakis N, Koumoundouros G, Kiparissis S, Somarakis S (2010) Defining length-at-metamorphosis in fishes: a multi-character approach. Mar Biol 157:991-1001

Osse JW, van den Boogaart JGM, van Snik GMJ, van der Sluys L (1997) Priorities during early growth of fish larvae. Aquaculture 155:249-258

Parichy DM, Elizondo MR, Mills MG, Gordon TN, Engeszer RE (2009) Normal table of postembryonic zebrafish development: staging by externally visible anatomy of the living fish. Dev Dyn 238:2975-3015

Park EH, Kim DS (1984) A procedure for staining cartilage and bone of whole vertebrate larvae while rendering all other tissues transparent. Stain Technol 59:269-272

Sfakianakis DG, Koumoundouros G, Divanach P, Kentouri M

Editorial responsibility: Christine Paetzold,

Oldendorf/Luhe, Germany
(2004) Osteological development of the vertebral column and of the fins in Pagellus erythrinus (L. 1758). Temperature effect on the developmental plasticity and morphoanatomical abnormalities. Aquaculture 232:407-424

Shea BT (1985) Bivariate and multivariate growth allometry: statistical and biological considerations. J Zool 206: 367-390

Somarakis S, Nikolioudakis N (2010) What makes a late anchovy larva? The development of the caudal fin seen as a milestone in fish ontogeny. J Plankton Res 32:317-326

Thorisson K (1994) Is metamorphosis a critical interval in the early life of marine fishes? Environ Biol Fish 40:23-36

Urho L (2002) Characters of larvae-what are they? Folia Zool (Brno) 51:161-186

> van Snik GMJ, van den Boogaart JGM, Osse JWM (1997) Larval growth patterns in Cyprinus caprio and Clarias gariepinus with the attention to the finfold. J Fish Biol 50: 1339-1352

Vigliola L, Harmelin-Vivien M (2001) Post-settlement ontogeny in three Mediterranean reef fish species of the genus Diplodus. Bull Mar Sci 68:271-286

Vigliola L, Harmelin-Vivien M, Biagi F, Galzin R and others (1998) Spatial and temporal patterns of settlement among sparid fishes of the genus Diplodus in the northwestern Mediterranean. Mar Eecol Prog Ser 168:45-56

Webb PW (1984) Body form, locomotion and foraging in aquatic vertebrates. Am Zool 24:107-120

Submitted: February 11, 2014; Accepted: May 27, 2014

Proofs received from author(s): Jule 9, 2014 